\title{
Interbirth interval and duration of pregnancy in hares
}

\author{
M. Stavy and J. Terkel \\ Department of Zoology, Tel Aviv University, Ramat Aviv 69978, Israel
}

\begin{abstract}
Summary. The possibility of inducing superfetation in hares by artificial insemination (AI) was investigated. AI performed on various days during the second half of gestation did not result in new pregnancies, but all ongoing pregnancies were terminated $1-4$ days after $\mathrm{Al}$. We suggest that copulation during the last week of pregnancy, common among captive hares, may have a similar effect to that of $\mathrm{AI}$ in terminating pregnancies and inducing early deliveries. Intervals between successive deliveries that are shorter than the normal duration of gestation do not necessarily indicate superfetation and this phenomenon may be rare among hares in captivity as well as in the wild.
\end{abstract}

Keywords: superfetation; artificial insemination; progesterone; hare

\section{Introduction}

Superfetation is defined as the initiation and development of a new pregnancy in already pregnant females. It is rare among mammals and has been described as a pathological disorder in several species (cows: Gee, 1971; Patas monkeys: Leakey, 1969; humans: Fontana \& Monif, 1970). European hares appear to be an exception: superfetation is considered a normal feature of the reproductive cycle. Hediger (1948) noticed that when hares copulate during late stages of pregnancy the interval between the next two deliveries is shortened. This was later confirmed by Bloch et al. (1967), who showed coexistence of a fetus, nearly ready to be delivered, and two fertilized ova (each divided into four cells) in the uterus of a pregnant hare. Although superfetation is apparently rare in hares in the wild (Raczynski, 1964; Flux, 1967; Broekhuizen \& Maaskamp, 1981), it appears to be common in captivity (Hediger, 1948; Bloch et al., 1954) and was observed by Martinet $e t$ al. (1970) in $66 \%$ of the pregnancies in their breeding colony. Most of the evidence supporting the existence of superfetation in the wild is direct and based on the coexistence in the uteri of nearly fully developed fetuses and fertilized ova at the first stages of division. In some cases (Martinet \& Reynaud, 1972) direct proof for ovulation and fertilization of a new set of ova during an ongoing pregnancy was also obtained in captivity. However, nearly all the evidence for the widespread existence of superfetation among captive hares is based on duration of intervals between successive deliveries (Martinet et al., 1970). These workers showed that whereas the usual gestation period was 40-42 days, shorter intervals of 24-39 days between successive deliveries occurred frequently in females that were permanently cohabiting with males. As the most common interval was 38 days, they concluded that the initiation of a new pregnancy usually overlapped with the ongoing one by 2-3 days. These data are also supported by later work showing that although matings occur in hares throughout gestation, their frequency increases after day 34 reaching a peak between days 38 and 40 of pregnancy (Caillol \& Martinet, 1983).

We have maintained a breeding colony of paired hares for over 10 years, but no cases of superfetation, as determined by shortened pregnancies, were observed. This difference from findings of other workers led us to investigate whether superfetation occurs in hares in Israel. The AI of hares, which was developed in our laboratory and has been used routinely as a breeding technique for captive hares (Stavy et al., 1978b), enabled us to control experimentally the timing of our attempts to induce superfetation. Our earlier work on the hormonal changes during pregnancy in the hare 
showed that a decrease in concentrations of progesterone (Stavy et al., 1978a) and an increase in concentrations of oestradiol and testosterone (Stavy, 1987; Stavy \& Terkel, 1984) occur at about day 38 of pregnancy, suggesting that a hormonal effect might facilitate superfetation. We therefore attempted to induce superfetation experimentally by AI at this stage of pregnancy.

\title{
Materials and Methods
}

\begin{abstract}
Animals
It is difficult to separate Lepus europaeus from Lepus capensis, and the exact taxonomic status of hares in Israel has not yet been established. It is, however, currently considered that the hares in the north of Israel, used in this study, belong to the species L. europaeus. (These hares have been the subject of our research for over ten years, but owing to the controversy about their taxonomy during this time, the name L. capensis was used in some of our previous publications.)

Hares used in the present study were 1-3 years old, and were either born in captivity (first and second generations) or collected in the field as leverets at an average age of 5 days, and raised in captivity. Experimental females were kept singly, and breeding pairs were permanently housed together in outdoor pens with a floor area of $1 \times 2 \mathrm{~m}$ (see Puget, 1970). All animals had free access to food (barley, lucerne, carrots and apples) and water.
\end{abstract}

\section{Artificial insemination}

Spermatozoa were obtained from the epididymides of anaesthetized males and diluted with physiological saline $\left(0.15 \mathrm{~mol} \mathrm{NaCl}^{-1}\right)$ to a final volume of $3-6 \mathrm{ml}$. The diluted suspension was stored at $15^{\circ} \mathrm{C}$ and used within $1 \mathrm{~h}$. Sperm motility was checked by microscope. The sperm suspension from each epididymis was sufficient for the insemination of 4-6 females. Ovulation was induced by intravenous injection of 50 iu human chorionic gonadotrophin (hCG) (Chorigon: Ikapharm, Israel). In preliminary tests, three doses of hCG $(25,50,100 \mathrm{iu})$ were used to induce ovulation in nonpregnant artificially inseminated females. Only two of $12(16.7 \%)$ females receiving 25 iu hCG became pregnant and delivered, whereas both 50 or $100 \mathrm{iu} \mathrm{hCG}$ resulted in mean pregnancy success of $77 \%$. The 50 iu hCG dose was therefore used. Immediately after hCG injection, approximately $0.7 \mathrm{ml}$ sperm suspension was introduced through a glass tube $(0.3 \mathrm{~cm}$ diameter) directly into the vagina of the hare (for details see Stavy et al., 1978b).

\section{Experimental procedure}

All experiments were performed on pregnant females that had conceived by means of AI. The day of insemination was considered day 1 of pregnancy. Superfetation was induced by inseminating pregnant females again at various times during gestation: six females were artificially inseminated between days 24 and 33 of pregnancy, 19 on day 38 and five on day 41 or 42 of pregnancy. The percentage of females that ovulated as a result of the hCG injection, but did not give birth, is not known, because no laparotomies were performed. Conception and superfetation during pregnancy were therefore determined only by the occurrence of a second delivery (or abortion).

The effects of each of the components of AI upon duration of gestation were determined: on day 38 of pregnancy six females were injected with $50 \mathrm{iu} \mathrm{hCG}$ and given vaginal stimulation (i.e. insertion of the glass tube described above, twice, into the vagina of the female); five females were given vaginal stimulation; and four females were injected with 50 iu hCG.

\section{Blood sampling}

Blood was collected from the ear vein into heparinized syringes. Five females, given AI on day 38 of pregnancy, were sampled $24 \mathrm{~h}$ before and $1,12,36$ and $48 \mathrm{~h}$ after insemination. The blood was centrifuged at $3000 \mathrm{~g}$ for $10 \mathrm{~min}$ at room temperature and the plasma stored at $-20^{\circ} \mathrm{C}$ until assayed.

\section{Measurement of progesterone}

A specific radioimmunoassay according to Stavy et al. (1978a) was used. Nonradioactive progesterone was purchased from Ikapharm (Israel) and $\left[1,2,6,7-{ }^{3} \mathrm{H}\right]$ progesterone (specific activity $94 \mathrm{Ci} \mathrm{mmol}^{-1}$ ) was obtained from the Radiochemical Centre, Amersham (UK). The assay was performed after petroleum ether (b.p. $40-60^{\circ} \mathrm{C}$ ) extraction. Bound and free fractions were separated using a dextran-charcoal mixture. The specificity of the antiserum (rabbit antiprogesterone-11-hemisuccinyl bovine serum albumin) has been described by Kohen \& Lindner (1975). Crossreactions with oestrogens, androgens and corticosteroids were $<0 \cdot 1 \%$. Blank values were below the sensitivity of the assay ( $15 \mathrm{pg}$ for the standard and $0.5 \mathrm{ng} \mathrm{ml}^{-1}$ plasma). Intra- and interassay coefficients of variation were $5 \cdot 1 \%$ and $10.0 \%$, respectively. 


\section{Measurement of oestradiol}

Total oestradiol was measured by radioimmunoassay as described by Yaron et al. (1977). Nonradioactive oestradiol was purchased from Sigma (Israel) and $\left[2,4,6,7,16,17-{ }^{3} \mathrm{H}\right]$ oestradiol (specific activity $155 \mathrm{Ci} \mathrm{mmol}^{-1}$ ) was obtained from the Radiochemical Centre, Amersham (UK). Plasma aliquots of 0.5-1.0 ml were extracted with cold diethyl ether. Bound and free fractions were separated on small Sephadex G-25 fine columns, prepared according to Basset \& Hinks (1969). The antiserum (rabbit anti-oestradiol-6-BSA serum) was a generous gift from Isodan Ltd (Israel); the major crossreactions were $0.47 \%$ and $0.2 \%$ with oestrone and oestriol, respectively. Blank values were below the sensitivity of the assay ( $2.0 \mathrm{pg}$ for the standard and $6.9 \mathrm{pg} \mathrm{m}^{-1}$ plasma). Intra- and interassay coefficients of variation were $4 \cdot 1$ and $17 \cdot 6 \%$, respectively.

\section{Statistical analysis}

All values are presented as means \pm SEM. A $t$-test comparison of a single test to a sample (Simpson et al., 1960) was used to compare an interval with the mean duration of the intervals between two successive deliveries. Comparisons of durations of pregnancies and body weights were done by Student's $t$-test. Analysis of the effect of the various treatments on the duration of gestation was performed by single classification ANOVA. Significance of the changes in progesterone and oestradiol concentrations were analysed by single classification ANOVA with repeated measurements, followed by Duncan's multiple range tests.

\section{Results}

\section{Gestation period}

The mean gestation period of artificially inseminated females $(n=51)$ was $45 \cdot 0 \pm 0 \cdot 19$ days, ranging between 43 and 48 days. The mean interval between successive deliveries of naturally breeding females (calculated for intervals under 49 days only, $n=31$ ) was $44 \cdot 8 \pm 0 \cdot 27$ days. There was no significant difference between the two mean values. Only one interval of less than 43 days was observed between two successive deliveries in a naturally breeding female. This interval of 41 days differed significantly from both means mentioned above $(P<0.01 ; P<0.02$, respectively).

One female, artificially inseminated on day 38 of pregnancy, aborted 22 days after insemination (19 days post delivery). None of the other inseminations performed on pregnant females resulted in pregnancy.

\section{Effect of artificial insemination on termination of pregnancy}

In all females, AI before day 34 of pregnancy resulted in abortion within 1-3 days after AI. Females inseminated on days 41 and 42 of gestation delivered normally within the expected time range. Most of the females artificially inseminated on day 38 of pregnancy delivered $1-4$ days later. The mean gestation period of these females $(41.47 \pm 0.29$ days $)$ was significantly shorter than that calculated for artificially inseminated nonpregnant females $(t=9 \cdot 77$; d.f. $=68, P<0 \cdot 0001)$.

\section{Hormonal response to artificial insemination during pregnancy}

Both progesterone and oestradiol plasma concentrations showed marked changes as a result of AI performed on day 38 of pregnancy. Within an hour after insemination progesterone concentration rose sharply and then gradually declined, reaching minimal values $36 \mathrm{~h}$ after insemination (Fig. 1). Changes in oestradiol concentrations, although less pronounced, generally followed the same pattern (Fig. 1). In one female, sampled for a longer period, plasma progesterone fell to $0.8 \mathrm{ng} \mathrm{ml}^{-1} 36 \mathrm{~h}$ after insemination and rose again to $8.9 \mathrm{ng} \mathrm{ml}^{-1} 84 \mathrm{~h}$ after insemination.

\section{Effect of the various components of artificial insemination on termination of gestation}

Vaginal stimulation and $\mathrm{hCG}$ injection resulted in early deliveries when given together or separately on day 38 of pregnancy. The effect of either or both treatments on the duration of gestation 


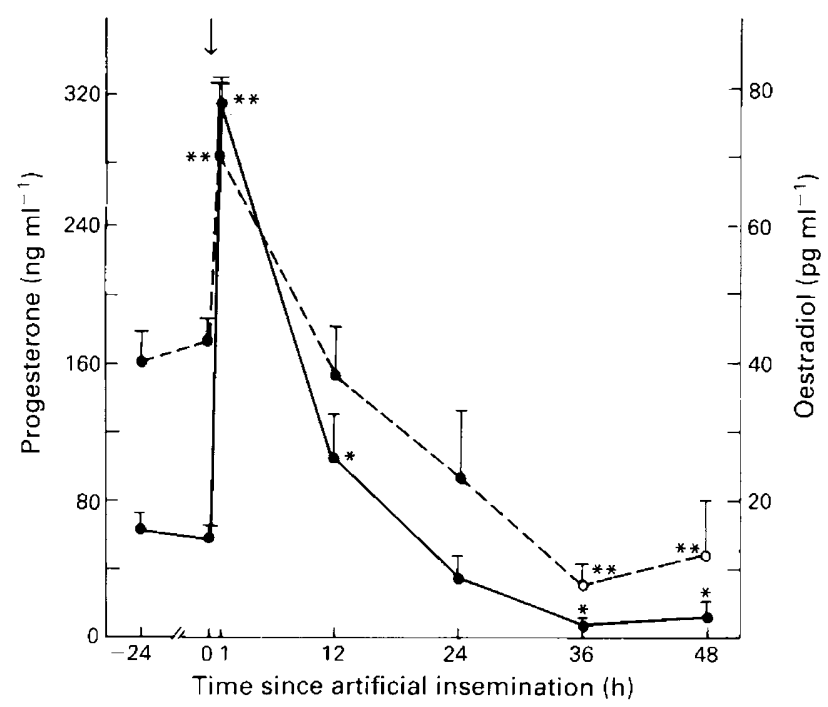

Fig. 1. Concentrations of progesterone (-) and oestradiol (- - ) in plasma of female hares ( $n=5, n=4$, respectively) before and after artificial insemination (indicated by arrow) performed on day 38 of pregnancy. Ovulation was induced by injection with 50 iu human chorionic gonadotrophin (hCG). Blood samples were taken (i) 24 hand (ii) immediately before insemination $(-24 \mathrm{~h}$ and $0 \mathrm{~h}$ ). All females were injected (i.v.) with 50 iu hCG immediately after the second blood sampling. Changes in hormone concentrations were statistically significant $(F=19.53$; d.f. $=$ $6.24 ; P<0.0001$ for progesterone and $F=10.48$; d.f. $=6.18 ; P<0.0001$ for oestradiol, by single classification ANOVA with repeated measures). Data are means \pm SEM. ${ }^{*} P<0.05 ;{ }^{* *} P<0.01$ in comparison with hormone concentrations at $0 \mathrm{~h}$ (by Duncan's multiple range tests).

was similar to that of the complete process of AI (Table 1). Of 44 early-born leverets, eight $(18 \cdot 18 \%)$ were still-born and $19(43 \cdot 18 \%)$ survived past the age of 3 months. These rates did not differ from those observed in leverets born at the end of full-term gestation $(n=241)$, among which $19.09 \%$ were still-born and $42.32 \%$ survived past the age of 3 months. A significant difference in body weight on the day of birth was found between early-born leverets $(n=14)$ and those born at the end of full-term gestation $(n=25)$. The mean body weights (calculated for leverets of litters of one and two only) were $118.71 \pm 4.69 \mathrm{~g}$ and $134.9 \pm 4.04 \mathrm{~g}$, respectively $(t=2.54$; d.f. $=37$; $P<0.02)$.

Table 1. Duration of ongoing gestation in untreated female hares and in females artificially inseminated (AI) or given vaginal stimulation, injection with $50 \mathrm{iu} \mathrm{hCG}$, both treatments on day 38 of pregnancy

\begin{tabular}{|c|c|c|c|c|c|c|}
\hline & & & Treatment & & & \\
\hline & None & AI & $\begin{array}{l}\text { Vaginal } \\
\text { stimulation } \\
+ \text { hCG }\end{array}$ & $\begin{array}{l}\text { Vaginal } \\
\text { stimulation }\end{array}$ & $\mathrm{hCG}$ & $P^{*}$ \\
\hline $\begin{array}{l}\text { Duration of } \\
\text { gestation (days) } \\
\text { Number of females }\end{array}$ & $45 \cdot 0 \frac{ \pm}{51} 0 \cdot 19$ & $41 \cdot 47 \pm 0.29^{a}$ & $41 \cdot 00 \pm \frac{0}{6} 0 \cdot 58^{a}$ & $41 \cdot 60 \frac{ \pm}{5} 0.87^{a}$ & $42.25 \pm 0.85^{\mathrm{a}}$ & $<0.0001$ \\
\hline
\end{tabular}




\section{Discussion}

In the present study AI performed at various phases of ongoing pregnancies did not result in the initiation of new pregnancies and hence, did not induce superfetation.

The similar mean birth interval in naturally breeding and artificially inseminated females shows that the permanent presence of males did not shorten intervals between successive deliveries. This is at variance with the observations of Martinet et al. (1970). Although the single interval of 41 days may be classified as a case of superfetation, no direct proof was obtained. Only one possible case of conception and partial development of a second pregnancy occurred after insemination on day 38 of pregnancy followed by abortion 22 days later.

Several field studies performed on the European hare reported superfetation in only $2-13 \%$ of the pregnancies, as shown by the coexistence of fetuses at two different developmental stages (Stieve, 1952; Raczynski, 1964; Flux, 1967). Other studies failed to confirm this phenomenon (Broekhuizen \& Maaskamp, 1981). The absence of superfetation among our naturally breeding females indicates that the failure to induce it experimentally did not result from technical factors. These data suggest that superfetation is not common in reproduction of hares in Israel and, if it exists, the frequency of its occurrence may be indicated by the two above-mentioned cases.

In all cases, AI performed before day 34 of pregnancy caused its termination within 2-3 days. Termination of pregnancy following hCG (or luteinizing hormone) injection has been observed in various mammals (e.g. rat: Banik, 1975; rabbit: Spies et al., 1966; Mills \& Gerardot, 1984; European hare: Martinet, 1980). In rabbits, oestrogen is the main luteotrophic factor (Hammond \& Robson, 195I; Miller \& Keyes, 1978), and administration of hCG to pregnant rabbits induces ovulation of the largest follicles which are the main source of the oestrogen (Osteen \& Mills, 1984). The sharp decline in oestrogen secretion that follows ovulation causes the degeneration of the corpora lutea, a drop in progesterone concentrations, and hence the termination of pregnancy (Keyes \& Nalbandov, 1968; Mills \& Gerardot, 1984). In a previous study we showed that the presence of the corpora lutea is essential as the main source of progesterone throughout pregnancy in hares (Stavy et al., 1978a). Induction of ovulation by hCG has also been shown in the pregnant hare (Martinet, 1980). We therefore suggest that the mechanism by which hCG terminates pregnancy in the hare is probably similar to that in the rabbit, although the luteotrophic and luteolytic factors involved in hares remain to be identified.

Artificial insemination performed on day 38 of pregnancy shortened it by an average of 3.5 days, as did hCG injection, vaginal stimulation or both (Table 1). The effect of AI was independent of its timing, since performance before day 34 or towards the end of pregnancy resulted in termination of pregnancy within the same period. However, on day 40 of pregnancy hare fetuses are already well developed (Broekhuizen \& Martinet, 1979) and are born alive, although small; thus termination of pregnancy at this stage can be considered as early delivery rather than abortion. While Martinet (1980) reported that the administration of hCG after day 32 of pregnancy did not result in its termination, her study presents data for four hares only, two of which delivered 3 days after the hCG administration; we suggest her findings do not necessarily contradict the results of the present study.

High concentrations of both progesterone and oestradiol were measured $1 \mathrm{~h}$ after AI performed on day 38 of pregnancy. These concentrations gradually declined, reaching minimal values after $36 \mathrm{~h}$. These changes are similar to those found in nonpregnant hares (Caillol \& Martinet, 1975; Stavy, 1976) and rabbits (Shaikh \& Harper, 1972; Waterson \& Mills, 1976; Wu et al., 1977) after hCG injection, resulting from a high level of steroid synthesis in the ovaries facilitated by the administered gonadotrophin (Eaton \& Hilliard, 1971; Lau et al., 1978). Similar changes in plasma progesterone concentrations were also found in the rabbit after hCG administration on day 21 of pregnancy, resulting in ovulation as well as corpora lutea degeneration and termination of pregnancy (Mills \& Gerardot, 1984). These results support our hypothesis that the mechanism of 
action of hCG in the hare is similar to that described in the rabbit. It is probable that the low concentrations of progesterone measured $36 \mathrm{~h}$ after insemination $\left(5.8 \mathrm{ng} \mathrm{ml}^{-1}\right)$, which were about $10 \%$ of the normal concentrations at this stage of gestation (Stavy et al., 1978a), were the direct cause of pregnancy termination. The gradual rise in concentrations of this steroid in the female sampled for a longer period may indicate the development of a new set of corpora lutea as a result of ovulation.

This study showed that vaginal stimulation alone, performed on day 38, resulted in the termination of pregnancy (Table 1). In the hare, as in the rabbit, ovulation is induced by copulation. However, inducing ovulation by mechanical and even electrical means, is difficult in rabbits (Sawyer, 1949; Carlyle \& Williams, 1961). Similarly, we have never succeeded in initiating pregnancy in a hare by using only vaginal stimulation to induce ovulation, making it unlikely that the introduction of a glass tube into the vagina of the hare caused ovulation and hence termination of pregnancy. However, it may have initiated termination of pregnancy through a different mechanism (possibly neural) which did not involve ovulation, but further work is necessary to clarify whether or not ovulation occurred.

The fact that AI, ovulation and vaginal stimulation on day 38 of pregnancy significantly shorten the duration of gestation, raises the question of whether the high percentage of superfetation in captive hares reported does not represent shortened gestations rather than overlapping of successive pregnancies. Only in a very few cases was superfetation proved, with evidence for ovulation, fertilization and implantation of a new set of ova during an ongoing pregnancy (Martinet \& Raynaud, 1972). In all other cases superfetation was deduced only when intervals between successive deliveries were shorter than the normal duration of gestation (Martinet et al., 1970).

Frequency of copulations in pregnant hares permanently kept with males increases towards the end of pregnancy (Hediger, 1948; Caillol \& Martinet, 1983). We therefore suggest that in most cases these copulations may result in termination of pregnancy and early deliveries, whereas the ensuing pregnancies are initiated during the period of post-partum oestrus, commonly observed in hares (Hediger, 1948; Lechleitner, 1959; Caillol \& Martinet, 1983). Both the 38-day intervals between deliveries reported by Martinet et al. (1970) (3-4 days less than the normal duration of gestation), and our data showing that the survival rates of early-born leverets did not differ from that of full-term births, support this hypothesis. If this is so, the phenomenon of superfetation would appear to be confined to conditions of captivity in which the male and female are permanently together. In nature, a shortened period of gestation, resulting in lower weight at birth, might be a disadvantage to the offspring.

We thank the keepers of the Canadian Center for Ecological Zoology for the expert care and management of the hare colony, in particular the director U. Marder, whose interest and painstaking assistance in this project made it possible. Thanks are also due to N. Paz and A. Terkel for help in the preparation of the manuscript, and to A. Shub and R. Suzin for the illustration.

\section{References}

Banik, U.K. (1975) Pregnancy-termination effect of human chorionic gonadotrophin in rats. Journal of Reproduction and Fertility 42, 67-76.

Basset, J.M. \& Hinks, N.T. (1969) Microdetermination of corticosteroids in ovine peripheral plasma: effect of venepuncture, corticotrophin, insulin and glucose. Journal of Endocrinology 44, 387-403.

Bloch, S., Hediger, H. \& Muller, H. (1954) Probleme der Fortpflanzung der Feldhasen. Revue Suisse de Biologie 61, 485-490.

Bloch, S., Hediger, H., Lloyd, H.G., Muller, C. \& Strauss, F. (1967) Beobachtungen zur Superfetation beim Feldhasen (Lepus europaeus). Journal Jagdwiss. $13,49-51$

Broekhuizen, S. \& Maaskamp, F. (1981) Annual production of young in European hares (Lepus europaeus) in the Netherlands. Journal of Zoology, London 193, 499-516.

Broekhuizen, S. \& Martinet, L. (1979) Growth of embryos of the European hare (Lepus europaeus Pallas). Zeitschrift fur Saugetierkunde 44, 175-179.

Caillol, M. \& Martinet, L. (1976) Preliminary results on plasma progesterone levels during pregnancy and superfetation of the hare, Lepus europaeus. Journal of Reproduction and Fertility 46, 61-64. 
Caillol, M. \& Martinet, L. (1983) Mating periods and fertility in the hare (Lepus europaeus) bred in captivity. Acta Zoologica Fennica 174, 65-68.

Carlyle, A. \& Williams, T.D. (1961) Artificially induced ovulation in the rabbit. Journal of Physiology 157, 42.

Eaton, L.W., Jr \& Hilliard, J. (1971) Estradiol 17- $\beta$, progesterone and 20-hydroxypregn-4-en-3-one in rabbit ovarian vein plasma. I. Steroid secretion from paired ovaries with and without corpora lutea: effect of $\mathrm{LH}$. Endocrinology 89, 105-111.

Flux, J.E.C. (1967) Reproduction and body weights of the hare Lepus europaeus Pallas in New Zealand. New Zealand Journal of Science 10, 357-401.

Fontana, J. \& Monif, G.R.G. (1970) Superfetation. Obstetrics and Gynecology 35, 585-588.

Gee, C.D. (1971) A case of superfetation in the cow. Australian Veterinary Journal 47, 179.

Hammond, J. \& Robson, J. (1951) Local maintenance of the rabbit corpus luteum with estrogen. Endocrinology 49, 384-389.

Hediger, H. (1948) Die Zucht des Feldhasen (Lepus europaeus Pallas) in Gefangenschaft. Physiologica Comparata et Oecologia 1, 46-62.

Keyes, P.L. \& Nalbandov, A.V. (1967) Maintenance and function of corpora lutea in rabbits depends on estrogen. Endocrinology 80, 938-946.

Kohen, F.S. \& Lindner, H.R. (1975) Preparation of antigenic steroid-protein conjugation. In Steroid Immunoassay, pp. 11-32. Eds E. H. O. Cameron, S. G. Hillier \& K. Griffiths. Alpha-Omega Publishing Ltd, Cardiff.

Lau, I.F., Saksena, S.K. \& Chang, M.C. (1978) Periovulatory steroid concentrations in HCG-treated rabbits. Hormone Research 9, 26-30.

Leakey, L.S.B. (1969) Presumed super-foetation in an Erythorcebus patas monkey. Nature 223, 754.

Lechleitner, R.R. (1959) Sex ratio, age classes and reproduction in the black-tailed jackrabbit. Journal of Mammalogy 40, 63-81.

Martinet, L. (1980) Oestrous behaviour, follicular growth and ovulation during pregnancy in the hare (Lepus europaeus). Journal of Reproduction and Fertility $\mathbf{5 9}$, $441-445$.

Martinet, L. \& Raynaud, F. (1972) Mécanisme possible de la superfoetation chez la hare. Comptes Rendus Academie de Sciences Paris 74, 2683-2686.

Martinet, L., Legouis, J.J. \& Moret, B. (1970) Quelques observations sur la reproduction du lièvre Européen (Lepus europaeus Pallas) en captivité. Annales de Biologie Animale, Biochimie, Biophysique 10, 195-202.

Miller, J.B. \& Keyes, P.L. (1978) Transition of the rabbit corpus luteum to estrogen dependence during early luteal development. Endocrinology 102, 31-38.

Mills, T.M. \& Gerardot, R.J. (1984) Dissociation of copulation from ovulation in pregnant rabbits. Biology of Reproduction 30, 1243-1252.
Osteen, K.G. \& Mills, T.M. (1984) In-vivo and in-vitro steroidogenic activity of post-ovulatory ovarian follicles of the rabbit. Journal of Reproduction and Fertility 70, 683-688.

Puget, A. (1970) Contribution à l'étude de l'élevage en captivité entroite de Lepus europaeus Pallas, 1778. Bulletin de Musée d'histoire naturelle de Paris 42, 1325-1333.

Raczynski, J. (1964) Studies on the European hare. V. Reproduction. Acta Theriologica 9, 305-352.

Sawyer, C.H. (1949) Reflex induction of ovulation in the estrogen-treated rabbit by artificial vaginal stimulation. Anatomical Record 103, 502.

Shaikh, A.A. \& Harper, M.J.K. (1972) Ovarian steroid secretion in estrous, mated and HCG treated rabbits, determined by current cannulation of both ovarian veins. Biology of Reproduction 7, 387-397.

Simpson, G., Roe, A. \& Lewontin, R.C. (1960) Quantitative Zoology. Harcourt, Brace \& Co., New York.

Spies, H.G., Coon, L.L. \& Gier, H.T. (1966) Luteolytic effect of $\mathrm{LH}$ and $\mathrm{HCG}$ on the corpora lutea of pseudopregnant rabbits. Endocrinology 78, 67-74.

Stavy, M. (1976) Aspects of rearing and reproduction of the hare (Lepus europaeus syriacus). MSc thesis, University of Tel Aviv.

Stavy, M. (1987) Endocrine, behavioural and social aspects of reproduction in the hare (Lepus capensis syriacus). PhD thesis submitted to the Senate of Tel Aviv University.

Stavy, M. \& Terkel, J. (1984) Plasma testosterone and oestradiol levels during pregnancy in the hare (Lepus capensis syriacus). Acta Zoologica Fennica 171, 169-171.

Stavy, M., Terkel, J. \& Kohen, F. (1978a) Plasma progesterone levels during pregnancy and pseudopregnancy in the hare (Lepus europaeus syriacus). Journal of Reproduction and Fertility 54, 9-14.

Stavy, M., Terkel, J. \& Marder, U. (1978b) Artificial insemination in the European hare (Lepus europaeus syriacus). Laboratory Animal Science 28, 163-166.

Stieve, H. (1952) Zur Fortpflanzungsbiologie des europaischen Feldhasen (Lepus europaeus Pallas). Zoologischer Anzeiger 148, 101-114.

Waterson, J.W. \& Mills, T.M. (1976) Peripheral blood steroid concentrations in the preovulatory rabbit. Journal of Steroid Biochemistry 7, 15-17.

Wu, C.H., Blasco, L., Flickinger, G.L. \& Mikhail, G. (1977) Ovarian function in the preovulatory rabbit. Biology of Reproduction 17, 304-308.

Yaron, Z., Terkatin-Shimony, A., Shaham, Y. \& Salzer, H. (1977) Occurrence and biological activity of estradiol $17-\beta$ in the intact and ovariectomized Tilapia aurea (Cichlidae, Teleostei). General and Comparative Endocrinology 33, 45-52.

Received 13 May 1991 